\title{
Is exposure to tobacco associated with extrahepatic cholangiocarcinoma epidemics? A retrospective proportional mortality study in China
}

Lei Hou ${ }^{1,3+}$, Jingmei Jiang ${ }^{1 * \dagger}$, Boqi Liu ${ }^{2,3 *}$, Wei Han ${ }^{1}$, Yanping Wu ${ }^{2}$, Xiaonong Zou², Fang Xue ${ }^{1}$, Yuanli Chen², Biao Zhang ${ }^{1}$, Haiyu Pang ${ }^{1}$, Yuyan Wang ${ }^{1}$, Zixing Wang ${ }^{1}$, Yaoda $\mathrm{Hu}^{1}$ and Junyao $\mathrm{Li}^{2}$

\begin{abstract}
Background: Extrahepatic cholangiocarcinoma (ECC) has become one of the most rapidly increasing malignancies in China during recent decades. The relationship between tobacco exposure and ECC epidemics is unclear; this study aimed to explore this relationship.

Methods: We included 55,806 participants aged 30 years or older from the National Mortality and Smoking Survey of China. Smoking in participants and spouses was defined as 1 cigarette or more per day for up to 1 year. Spouses' smoking was taken as a measure of exposure to passive smoking. Smoking information in 1980 was ascertained and outcomes were defined as ECC mortality during 1986-1988.

Results: We found that either passive or active smoking increased the risk of death from ECC by $20 \%$ (risk ratio [RR], 1.20; 95\% confidence interval [Cl], 0.99-1.47), compared with no exposure to any tobacco. This risk was a notable $98 \%$ (RR, 1.98; 95\% Cl, 1.49-2.64) for individuals exposed to passive plus active smoking. These findings were highly consistent among men and women. Pathology-based analyses showed dose-response relationships of ECC with pack-years for all types of smoking exposure ( $\mathrm{PS}$ for trend $<0.05)$; the RR reached $2.75(95 \% \mathrm{Cl}, 1.20-6.30)$ in individuals exposed to combined smoking with the highest exposure dose. The findings were similar for nonpathology-based analysis.

Conclusions: This study indicates that tobacco exposure increases ECC risk. Given the dramatic increase of exposure to secondhand smoke and patients with ECC, an inadequate provision of smoke-free environments could be contributing to ECC epidemics and could further challenge public health and medical services, based on the current disease spectrum.
\end{abstract}

Keywords: Smoking, Cholangiocarcinoma, Mortality, Population

\footnotetext{
* Correspondence: jingmeijiang@ibms.pumc.edu.cn; boqiliu@163.com

${ }^{+}$Lei Hou and Jingmei Jiang are joint first authors.

'Department of Epidemiology and Biostatistics, Institute of Basic Medical Sciences Chinese Academy of Medical Sciences / School of Basic Medicine Peking Union Medical College, A505 Room Mingri Building, 5

Dongdansantiao Street, Dongcheng District, Beijing 100005, China

${ }^{2}$ Cancer Institute \& Hospital, Chinese Academy of Medical Sciences / Peking

Union Medical College, Beijing, China

Full list of author information is available at the end of the article
}

(c) The Author(s). 2019 Open Access This article is distributed under the terms of the Creative Commons Attribution 4.0 International License (http://creativecommons.org/licenses/by/4.0/), which permits unrestricted use, distribution, and reproduction in any medium, provided you give appropriate credit to the original author(s) and the source, provide a link to the Creative Commons license, and indicate if changes were made. The Creative Commons Public Domain Dedication waiver (http://creativecommons.org/publicdomain/zero/1.0/) applies to the data made available in this article, unless otherwise stated. 


\section{Background}

High incidence rates of cholangiocarcinoma (CC) $(>6$ per 100,000 people) have been reported in countries of Eastern Asia, such as in China, though this cancer is relatively rare worldwide [1]. CC accounts for $10-20 \%$ of deaths owing to hepatobiliary malignancies, which are the second most common cause of death from cancer in China [2,3]. Given its resistance to current treatments and poor prognosis, the mortality and incidence of $\mathrm{CC}$ are virtually the same. From an anatomical viewpoint, $\mathrm{CCs}$ are classified as intrahepatic (ICC) or extrahepatic (ECC). ECC has been documented to account for about $90 \%$ of CCs [4]. In the Americas, $65 \%$ of ECC cases occur in the seventh decade of life [5]. By contrast, our data suggest that there are many middle-aged people with ECC cases among the Chinese population. Compared with a rising trend in ICC, the incidence of ECC seems to be decreasing or remaining constant in most developed countries, such as the United Kingdom and the United States (US) [6, 7]. However, for reasons that are unclear, the ECC appears to be one of the most rapidly increasing cancers in China, in areas such as urban Shanghai $[8,9]$.

Most cases of ECC are considered de novo with no apparent cause, although several risk factors of CC have been established, such as parasitic infection and hepatolithiasis especially associated with ICC and primary sclerosing cholangitis mainly linked with perihilar CC [3-5]. A recent experimental study indicates that nicotine, a major active component of cigarette smoke, contributes to biliary fibrosis by activation of cholangiocyte proliferation and expression of profibrotic genes [10]. Tobacco smoking is associated with the reduction of p53, a tumor suppressor gene [11], and suppression of T-cell responses by nicotine; in addition, tar is associated with decreased immune surveillance of tumor cells [12]. The experiences of developed countries indicate that tobacco control accounts for nearly all improvements in mortality rates for smoking-related malignancies during the past four decades. However, smoking is currently not an established risk factor of ECC [13]. Despite China having the largest population exposed to tobacco worldwide and a rapidly rising number of ECC cases [14, 15], studies did not indicate an association of smoking with ECC in this population. With a recent systematic review [16], we re-pooled the odds ratios (ORs) of four case-control studies conducted among the Chinese population and still found a negative association between smoking and ECCs $\left(I^{2}=3.0 \%, P\right.$ for $I^{2}=0.377$; OR, 1.00; 95\% confidence interval [CI], 0.78-1.22); hospital-based design and a small sample size could contribute to this negative finding. Research conducted on the association between exposure to passive smoking and ECC is lacking worldwide. In the absence of cohort studies, results from case-control studies have provided little evidence on active smoking. Two population-based case-control studies from North America indicated an association between active smoking and ECC [17, 18]; however, other studies from the Netherlands, Italy, and the US did not support this association [19-23].

In any case, smoking is suspected to contribute to this rapidly rising cancer [8]. The aim of the current study is to explore the relationship of tobacco exposure with ECC epidemics by investigating the association between passive or active cigarette smoking, or both, and ECC mortality in Chinese people.

\section{Methods}

\section{Study population}

The China Nationwide Retrospective Mortality Survey included 1,136,686 all-cause deaths among participants aged 30 years or older during 1986-1988, in 24 cities that were the largest in their provinces and 79 rural counties randomly chosen from over 2000 counties in China. These 103 areas covered all geographic and economic zones across 28 provincial administrative regions of China. We identified deaths primarily using local administrative records and medical records. The underlying cause of each death was coded according to the International Classification of Diseases, 9th Revision (ICD-9). Over 500 trained interviewers usually worked as teams of two in urban areas and teams of four in rural areas. Detailed information on this survey has been described elsewhere [24-29].

We included 565,266 married people who had no missing data on gender, age of spouse, and history of tobacco use, to establish this longitudinal-like observed population. We excluded 269,623 participants that died from cardiovascular and respiratory diseases, which are closely associated to tobacco exposure and likely to affect exposure measurement owing to behavior changes after the occurrence of these diseases. In addition, to ensure an initially CC-free status at baseline, we excluded 211,128 participants that died from communicable diseases, digestive diseases, and malignant tumors other than CC. In a comparison between other excluded participants with the remaining participants (Additional file 1: Table S1), we found that excluded individuals with other diseases-who had the most missing data-had a relatively high rate of exposure to both active and passive smoking. Moreover, to avoid bias owing to recall and diagnostic misclassification, we retained only those participants with a smoking history-as recalled by living spouses $(74.0 \%)$, children $(24.2 \%)$, or parents $(1.8 \%)$ who had usually lived with the deceased person for a long time-and those with clinical diagnoses or higher. Finally, after excluding 13 ICC cases, a total of 55,806 participants were included in this retrospective proportional 
mortality study. Details of enrollment of the study population are shown in Fig. 1.

\section{Definitions of exposure and grouping}

Spouses or other relatives of all deceased persons were interviewed, to obtain information on participants' smoking history during this mortality survey. Interviewees retrospectively described the smoking habits of the deceased participants, as well as their own, in the year 1980; this guaranteed to minimize effects of behavior changes after the participant was diagnosed with ECC. Smoking in participants and spouses was defined as $\geq 1$ cigarette per day for up to 1 year. Spouses' smoking was taken as a measure of exposure to passive smoking among participants. To define exposure-years of passive smoking, we used 20 years as the cut-off age for beginning smoking because we had no data on the participants' date of marriage. Age 20 years is an acceptable

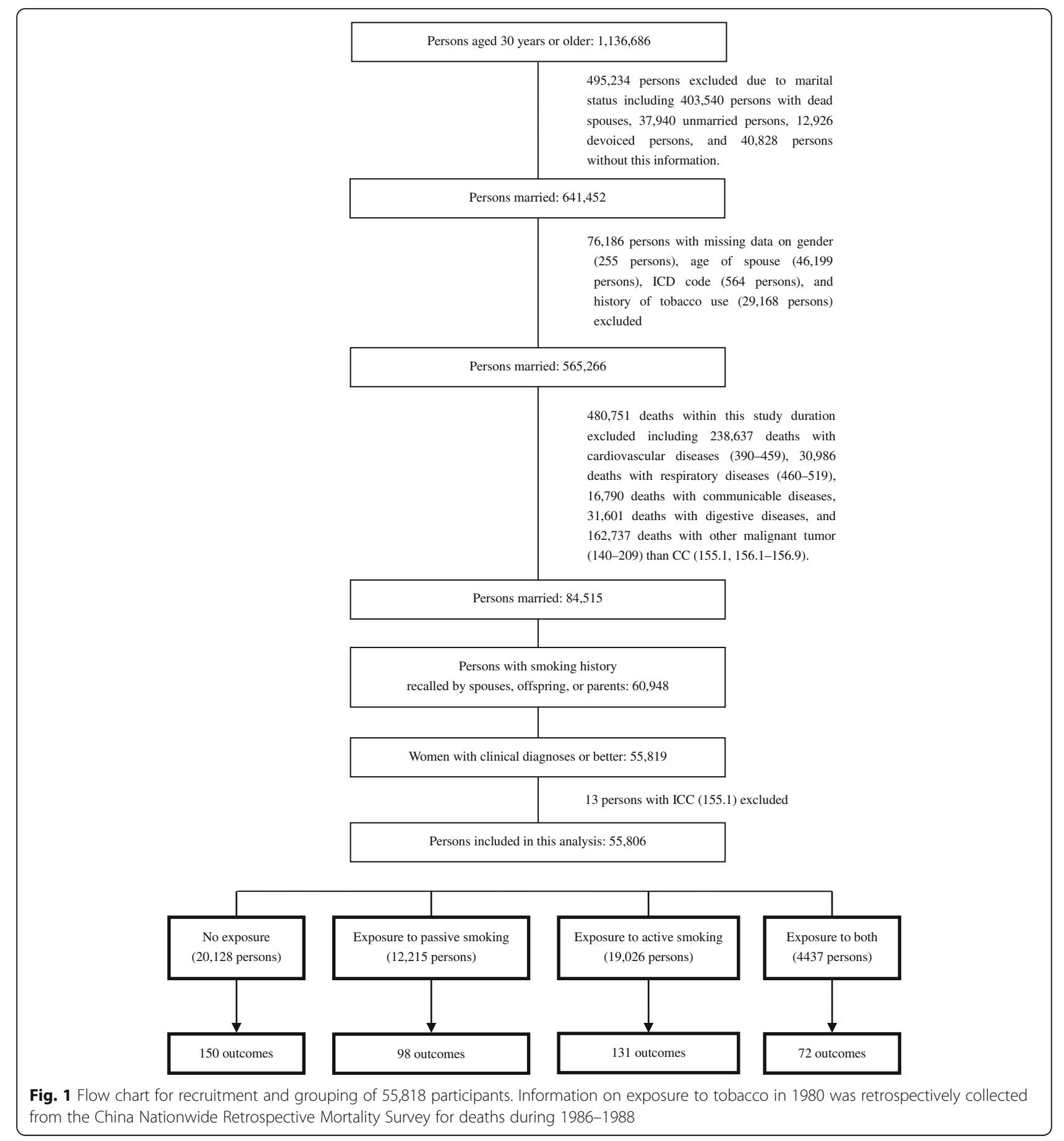


and likely cut-off because this was a common age for marriage before the foundation of the People's Republic of China in 1949 [30]. For spouses who began to smoke at age 20 years or older, we defined years of passive smoking as the age at death for cases or controls minus the age at onset of daily smoking. For spouses who began to smoke before age 20 years, the number of years of smoking before this age was further subtracted [27]. Accordingly, these participants were divided into control and exposure groups (20,128 vs. 35,678 participants), according to smoking information in 1980. The control group was defined as participants with no exposure to tobacco, including passive smoking and active smoking. Individuals exposed to any tobacco use were defined as the exposure group, including nonsmokers exposed to passive smoking (12,215 participants, $21.9 \%$ in total), smokers unexposed to passive smoking (19,026 participants, $34.1 \%$ ), and smokers exposed to passive smoking (4437 participants, $7.9 \%$ ).

\section{Ascertainment of ECC}

Outcomes were defined as ECC deaths during 19861988 after exposure to tobacco (prior to 1980). In this national mortality survey, we ascertained 451 cases of ECC (ICD-9 code: 156.1-156.9), accounting for $97.2 \%$ of all CC. These ECC cases were confirmed by autopsy, histological examination, surgical procedure, clinical assessment including imaging and laboratory testing, and clinical manifestations $(0.7,29.7,12.2,54.3$, and $3.1 \%$ of total cases, respectively). Pathology-based diagnoses-including autopsy, histological examination, and surgical procedure which are authorized as the highest category of diagnosis in the national death surveillance system of China-were performed with 42.6\%. 50.3, 32.4, and $12.9 \%$ of diagnoses were determined at provincial-, prefectural-, and county-level hospitals, respectively. Among 451 deaths owing to ECC, 24 patients have other digestive diseases including 19 related to the gallbladder and biliary tract (ICD-9 codes: 574-576, 188), 3 related to the liver (ICD-9 codes: 571, 573), and 2 related to the gastrointestinal tract (ICD-9 codes: 538, 560). A total 150, 98, 131, and 72 of the 451 deaths occurred in the control group and the three exposure groups listed above.

\section{Statistical methods}

Mean \pm standard deviation and person-number (percentage in total) were used for presenting continuous and categorical variables, respectively. We calculated risk ratios (RRs) with 95\% confidence intervals (CIs) comparing smokers and nonsmokers. RRs were estimated using unconditional logistic regression models [24, 25]. The initial models (Model 1) were adjusted for age as well as gender if applicable. The fully adjusted models (Model 2) further included variables that could affect association with both exposure and outcomes, including age, gender, urban or rural residence, ethnicity, and education; if applicable, the model also included either passive or active smoking and presence or absence of pathology-based diagnoses. In the interest of investigating a dose-response relationship, we defined 1 pack-year as 20 cigarettes smoked per day for 1 year. For smokers exposed to passive smoking, pack-years of passive plus active smoking were defined as active smoking multiplied by passive smoking; this was owing to the likely weak effect of each single variable on outcomes, including passive or active smoking, years of exposure, and cigarettes smoked per day.

Sensitivity analysis was used to assess the robustness of validity. First, ECC-free status at baseline was considered. The 5-year survival rate for ECC was approximately $10 \%$ during $1979-2004$ in the US [31]; this rate was likely lower in China. In other words, among all ECC deaths in our survey, there were very few participants with ECC (e.g., < 10\%) in 1980, when their smoking status was affirmed. Accordingly, $10 \%$ of deaths owing to ECC in each subgroup by gender and 10-year age span were randomly deleted from the participant database and a reanalysis was carried out. In addition, non-pathology-based diagnoses or digestive diseases other than ECC are factors that likely lead to misclassification of outcomes; therefore, in a random stepwise manner, we changed $10,20,30 \%, \ldots, 100 \%$ of these ECC deaths to non-outcomes and recalculated the effect values. Lastly, to elaborate the variable of exposure to passive smoking, we showed the results considering the assumed age of marriage.

All analyses were performed using SAS 9.2 statistical software (SAS Institute, Inc., Cary, NC, USA). All $P$-values were two sided except $P$ trend tests based on unconditional logistic regression, in which one-sided $P$ values were used. A $P$-value $<0.05$ was considered statistically significant.

\section{Results}

Similar characteristics of gender, age, residence, ethnicity, and education level were observed between controls and participants exposed to tobacco. We also found large differences in these characteristics between the three exposure groups (Table 1); however, these participants with exposure to tobacco had median exposure time of 30 years or over and a median daily exposure of 10 cigarettes, for both passive and active smoking; this resulted in a generally long pack-year history in this population.

The fully-adjusted model showed that exposure to tobacco increased the risk of death from ECC by $20 \%$ with marginal statistical significance (RR, 1.20; 95\% CI, 0.991.47), as compared with non-exposure. However, this 
Table 1 Characteristics of control and tobacco-exposure groups

\begin{tabular}{|c|c|c|c|c|c|c|}
\hline & Controls & Exposure to & $\mathrm{acco}$ & & & Total \\
\hline & & Passive & Active & Passive \& Active & All & \\
\hline Men (\%) & 59.3 & 9.2 & 95.5 & 63.6 & 62.0 & 61.0 \\
\hline Age (years) & $57.9 \pm 15.7$ & $53.4 \pm 14.5$ & $56.9 \pm 14.9$ & $63.5 \pm 11.2$ & $56.6 \pm 14.7$ & $57.0 \pm 15.1$ \\
\hline Urban residence (\%) & 75.8 & 70.7 & 72.3 & 86.3 & 73.5 & 74.3 \\
\hline Han nationality (\%) & 95.4 & 96.6 & 95.6 & 97.8 & 96.2 & 95.9 \\
\hline Education (\%) & & & & & & \\
\hline College or university & 5.5 & 1.6 & 3.2 & 2.1 & 2.5 & 3.6 \\
\hline Middle school & 26.0 & 20.1 & 28.4 & 16.6 & 24.1 & 24.8 \\
\hline Primary school & 35.1 & 32.9 & 42.1 & 41.8 & 38.9 & 37.5 \\
\hline Illiteracy & 31.7 & 43.9 & 25.1 & 38.4 & 33.2 & 32.6 \\
\hline Unknown & 1.8 & 1.6 & 1.3 & 1.2 & 1.4 & 1.5 \\
\hline Years exposed to passive smoking & - & $30(18-40)$ & - & $36(26-44)$ & - & - \\
\hline Cigarettes passively smoked daily & - & $10(6-20)$ & - & $10(4-17)$ & - & - \\
\hline Pack-years exposed to passive smoking & - & $15(6-27)$ & - & $14(4-27)$ & - & - \\
\hline Years exposed to active smoking & - & - & $34(21-46)$ & $40(30-49)$ & - & - \\
\hline Cigarettes actively smoked daily & - & - & $10(6-20)$ & $10(5-20)$ & - & - \\
\hline Pack-years exposed to active smoking & _- & _- & $17(7-32)$ & $19(6-35)$ & _- & _- \\
\hline
\end{tabular}

risk was much different when comparing the three exposure subgroups to controls. RRs were 1.15 (0.86-1.55) and $1.11(0.85-1.44)$ for nonsmokers exposed to passive smoking and for smokers unexposed to passive smoking, respectively; for smokers exposed to passive smoking, the RR increased dramatically to 1.98 (1.49-2.64). These findings were highly consistent among both male and female participants as well as between pathology-based and non-pathology-based analyses (Table 2). Among participants with ECCs, 2.4, 8.9, 28.4, 37.7, 20.8, and $1.8 \%$ were in the age of $30-39,40-49, \ldots, 70-79$, and 80 years or older, respectively. RRs for an association between exposure to passive plus active smoking and ECC death were strongly influenced by age, and both crude and adjusted RRs began increasing at age 50 years.

We used pack-years to demonstrate a dose-response relationship owing to a weak effect of single variables for tobacco exposure on this disease (Table 3 and Fig. 2). In the pathology-based analysis, the highest dose of pack-years $(\geq 20)$ increased the risk of ECC mortality by $60 \%$ (RR, 1.60; 95\% CI, 0.94-2.75) for passive smoking ( $P$ for trend $=0.021)$ and $66 \%(\mathrm{RR}, 1.66$; 95\% CI, $1.03-$ 2.67 ) for active smoking ( $P$ for trend $=0.045$ ), compared with controls. We further combined non-smokers exposed to passive smoking and smokers unexposed to passive smoking as a single exposure group and divided smokers exposed to passive smoking into three exposure subgroups with stepwise increasing doses, i.e., less than $400,400-799$, and 800 pack-years squared or more. The risk of ECC death significantly increased with increasing exposure dose $(P$ for trend $<0.001)$. This risk dramatically increased to 2.75 fold ( $R R, 2.75$; 95\% CI, 1.20-6.30) in participants with the highest exposure dose, compared with controls. These findings were highly consistent in the non-pathology-based analysis.

A sensitivity analysis showed that our results were robust. After randomly deleting $10 \%$ of deaths owing to ECC were randomly deleted from the participant group, compared with non-exposure, the risk of death from ECC increased by 9\% (RR, 1.09; 95\% CI, 0.80-1.50), 20\% (RR, 1.20; 95\% CI, 0.91-1.59), 113\% (RR, 2.13; 95\% CI, $1.58-2.87$ ), and $23 \%$ (RR, 1.23 ; 95\% CI, 1.00-1.52) for the three exposure groups and all exposed participants, respectively. After 269 cases with non-pathology-based diagnoses or digestive diseases other than ECC were changed to non-outcomes, the risks increased by $34 \%$ (RR, 1.34; 95\% CI, 0.81-2.21), 38\% (RR, 1.38; 95\% CI, $0.90-2.12$ ), $152 \%$ (RR, 2.52; 95\% CI, 1.58-4.00), and 39\% (RR, 1.39; 95\% CI, 1.00-1.93), respectively. The findings retained robust with $10-90 \%$ of these cases changed (Table 4). In addition, the assessment of smoking in either spouse or parents/children did not show likelihood of recall bias; the RRs for all exposed participants were 1.21 (95\% CI, 0.96-1.52) and 1.19 (95\% CI, 0.81-1.75), respectively. Moreover, owing to age of marriage, some participants with spouses who smoked would not actually be exposed to passive smoking. Additional file 1: Table S2 shows RRs under the assumed age of marriage 20 years old. When changing this to age 25 or 30 years, the results were retained. 
Table 2 Gender-, age-, and diagnosis-specific relationship between exposure to tobacco and death owing to extrahepatic cholangiocarcinoma

\begin{tabular}{|c|c|c|c|c|c|}
\hline & \multirow{2}{*}{$\begin{array}{l}\text { Numbers } \\
\text { of } \\
\text { outcomes }\end{array}$} & \multirow{2}{*}{$\begin{array}{l}\text { Numbers } \\
\text { of } \\
\text { persons } \\
\text { observed }\end{array}$} & \multirow[t]{2}{*}{$\%$} & \multicolumn{2}{|l|}{ RR $(95 \% \mathrm{Cl})$} \\
\hline & & & & Model 1 & Model 2 \\
\hline \multicolumn{6}{|l|}{ Men } \\
\hline Control & 86 & 11,937 & 7.2 & 1.00 & 1.00 \\
\hline Passive & 14 & 1122 & 12.5 & $1.61(0.91-1.85)$ & $1.56(0.88-2.79)$ \\
\hline Active & 115 & 18,162 & 6.3 & $0.93(0.70-1.23)$ & $0.97(0.73-1.29)$ \\
\hline Passive \& Active & 39 & 2820 & 13.8 & $1.81(1.23-2.66)$ & $1.67(1.14-2.46)$ \\
\hline \multicolumn{6}{|l|}{ Women } \\
\hline Control & 64 & 8191 & 7.8 & 1.00 & 1.00 \\
\hline Passive & 84 & 11,093 & 7.6 & $1.08(0.77-1.50)$ & $1.09(0.78-1.52)$ \\
\hline Active & 16 & 864 & 18.5 & $2.15(1.23-3.74)$ & $1.96(1.16-3.43)$ \\
\hline Passive \& Active & 33 & 1617 & 20.4 & $2.46(1.61-3.76)$ & $2.56(1.66-3.94)$ \\
\hline \multicolumn{6}{|l|}{ 30 49 years } \\
\hline Control & 21 & 6320 & 3.3 & 1.00 & 1.00 \\
\hline Passive & 17 & 4971 & 3.4 & $1.31(0.58-2.99)$ & $1.49(0.63-3.43)$ \\
\hline Active & 11 & 6091 & 1.8 & $0.52(0.23-1.16)$ & $0.56(0.25-1.25)$ \\
\hline Passive \& Active & 2 & 456 & 4.4 & $0.91(0.21-3.96)$ & $0.98(0.22-4.27)$ \\
\hline \multicolumn{6}{|l|}{ 50 69 years } \\
\hline Control & 89 & 8457 & 10.5 & 1.00 & 1.00 \\
\hline Passive & 67 & 5333 & 12.6 & $1.07(0.75-1.54)$ & $1.07(0.75-1.54)$ \\
\hline Active & 94 & 8551 & 11.0 & $1.23(0.88-1.71)$ & $1.25(0.90-1.75)$ \\
\hline Passive \& Active & 48 & 2587 & 18.6 & $1.75(1.23-2.49)$ & $1.72(1.20-2.46)$ \\
\hline \multicolumn{6}{|l|}{ 70 98 years } \\
\hline Control & 40 & 5351 & 7.5 & 1.00 & 1.00 \\
\hline Passive & 14 & 1911 & 7.3 & $1.08(0.56-2.10)$ & $1.09(0.56-2.11)$ \\
\hline Active & 26 & 4384 & 5.9 & $0.76(0.45-1.29)$ & $0.77(0.45-1.30)$ \\
\hline Passive \& Active & 22 & 1394 & 15.8 & $1.96(1.16-3.33)$ & $1.84(1.08-3.13)$ \\
\hline \multicolumn{6}{|l|}{ Pathology-based } \\
\hline Control & 54 & 4501 & 12.0 & 1.00 & 1.00 \\
\hline Passive & 45 & 2971 & 15.1 & $1.35(0.83-2.19)$ & $1.41(0.87-2.28)$ \\
\hline Active & 62 & 5537 & 11.2 & $1.25(0.82-1.90)$ & $1.26(0.89-2.07)$ \\
\hline Passive \& Active & 31 & 836 & 37.1 & $2.50(1.59-3.93)$ & $2.38(1.50-3.77)$ \\
\hline \multicolumn{6}{|l|}{ Non-pathology-based } \\
\hline Control & 96 & 15,627 & 6.1 & 1.00 & 1.00 \\
\hline Passive & 53 & 9244 & 5.7 & $0.98(0.67-1.43)$ & $1.00(0.69-1.46)$ \\
\hline Active & 69 & 13,489 & 5.1 & $0.91(0.65-1.28)$ & $0.96(0.68-1.35)$ \\
\hline Passive \& Active & 41 & 3601 & 11.4 & $1.79(1.23-2.58)$ & $1.72(1.19-2.50)$ \\
\hline \multicolumn{6}{|l|}{ Total } \\
\hline Control & 150 & 20,128 & 7.5 & 1.00 & 1.00 \\
\hline Passive & 98 & 12,215 & 8.0 & $1.15(0.86-1.53)$ & $1.15(0.86-1.55)$ \\
\hline Active & 131 & 19,026 & 6.9 & $1.08(0.83-1.41)$ & $1.11(0.85-1.44)$ \\
\hline Passive \& active & 72 & 4437 & 16.2 & $2.06(1.55-2.73)$ & $1.98(1.49-2.64)$ \\
\hline
\end{tabular}


Table 3 Dose-response relationship between exposure to either passive or active smoking and deaths owing to extrahepatic cholangiocarcinoma

\begin{tabular}{|c|c|c|c|c|c|}
\hline \multirow{2}{*}{$\begin{array}{l}\text { Doses exposed to tobacco } \\
\text { (pack-years) }\end{array}$} & \multirow{2}{*}{$\begin{array}{l}\text { Numbers } \\
\text { of } \\
\text { outcomes }\end{array}$} & \multirow{2}{*}{$\begin{array}{l}\text { Numbers } \\
\text { of } \\
\text { persons } \\
\text { observed }\end{array}$} & \multirow[t]{2}{*}{$\%$} & \multicolumn{2}{|l|}{ RR $(95 \% \mathrm{Cl})$} \\
\hline & & & & Model 1 & Model 2 \\
\hline \multicolumn{6}{|l|}{ Pathology-based } \\
\hline Control & 54 & 4501 & 12.0 & 1.00 & 1.00 \\
\hline \multicolumn{6}{|c|}{ Exposure to passive smoking } \\
\hline $1 \sim 9$ & 81 & 6976 & 11.6 & $1.13(0.66-1.96)$ & $0.94(0.46-1.95)$ \\
\hline $10 \sim 19$ & 17 & 1105 & 15.4 & $1.62(0.90-2.91)$ & $1.09(0.51-1.36)$ \\
\hline$\geq 20$ & 40 & 1267 & 31.6 & $1.97(1.24-3.15)$ & $1.60(0.94-2.75)$ \\
\hline$P$ for trend & & & & $<0.001$ & 0.021 \\
\hline \multicolumn{6}{|l|}{ Exposure to active smoking } \\
\hline $1 \sim 9$ & 70 & 5271 & 13.3 & $1.12(0.68-1.85)$ & $0.86(0.45-1.63)$ \\
\hline $10 \sim 19$ & 20 & 1646 & 12.2 & $1.59(0.91-2.75)$ & $1.26(0.65-1.41)$ \\
\hline$\geq 20$ & 48 & 2428 & 19.8 & $1.78(1.15-2.76)$ & $1.66(1.03-2.67)$ \\
\hline$P$ for trend & & & & 0.002 & 0.045 \\
\hline \multicolumn{6}{|l|}{ Non-pathology-based } \\
\hline Control & 96 & 15,627 & 6.1 & 1.00 & 1.00 \\
\hline \multicolumn{6}{|c|}{ Exposure to passive smoking } \\
\hline $1 \sim 9$ & 95 & 17,933 & 5.3 & $1.04(0.67-1.63)$ & $0.79(0.42-1.48)$ \\
\hline $10 \sim 19$ & 16 & 3276 & 4.9 & $0.86(0.50-1.49)$ & $0.79(0.41-1.52)$ \\
\hline$\geq 20$ & 52 & 5133 & 10.1 & $1.61(1.12-2.32)$ & $1.27(0.81-1.98)$ \\
\hline$P$ for trend & & & & 0.013 & 0.220 \\
\hline \multicolumn{6}{|l|}{ Exposure to active smoking } \\
\hline $1 \sim 9$ & 83 & 14,506 & 5.7 & $1.08(0.70-1.64)$ & $0.73(0.40-1.34)$ \\
\hline $10 \sim 19$ & 18 & 3498 & 5.1 & $0.92(0.55-1.56)$ & $0.95(0.53-1.70)$ \\
\hline$\geq 20$ & 62 & 8330 & 7.4 & $1.24(0.88-1.76)$ & $1.08(0.73-1.60)$ \\
\hline$P$ for trend & & & & 0.066 & 0.431 \\
\hline
\end{tabular}

\section{Discussion}

This is the first study indicating an association between exposure to tobacco and ECCs in China. Our main findings showed that exposure to tobacco, particularly passive plus active smoking, increased the risk of death owing to ECC with a significant dose-response relationship.

Our findings are supported by reports on the contribution of cigarette smoke to malignant change in biliary cells [19-21]. However, our study differs from previous observational studies that have discussed the effect of active smoking but have lacked information about passive smoking. Our controls had no exposure to either passive or active smoking, based on information of passive smoking obtained from family members; therefore, we could simultaneously observe the effects of passive, active, and passive plus active smoking on ECC. Our study highlighted that a high interaction between passive smoking and active smoking could contribute to ECC mortality, as suggested by other studies on the association between smoking and cancers such as cervical cancer [28]. Based on our control design and a large number of participants with long-term heavy exposure to tobacco in our database (Table 1), we could further define multiple doses of exposure to passive plus active smoking by combining information on both passive and active smoking with years of smoking and cigarettes smoked daily. Using pack-years squared exposed, we found a 2.75-fold increased risk of ECC mortality in the exposure group with the highest dose, as compared with controls.

Our study is especially practical for the prevention and control of this rapidly increasing fatal disease in the Chinese population. China has 300 million smokers and a relatively stable pattern of active smoking, reflected in the prevalence rates and cigarettes smoked daily [29, 32]. However, the exposure rate to secondhand smoke among nonsmokers dramatically increased by $80 \%$ during 1984-2010, from 40 to $72.4 \%$, following a 


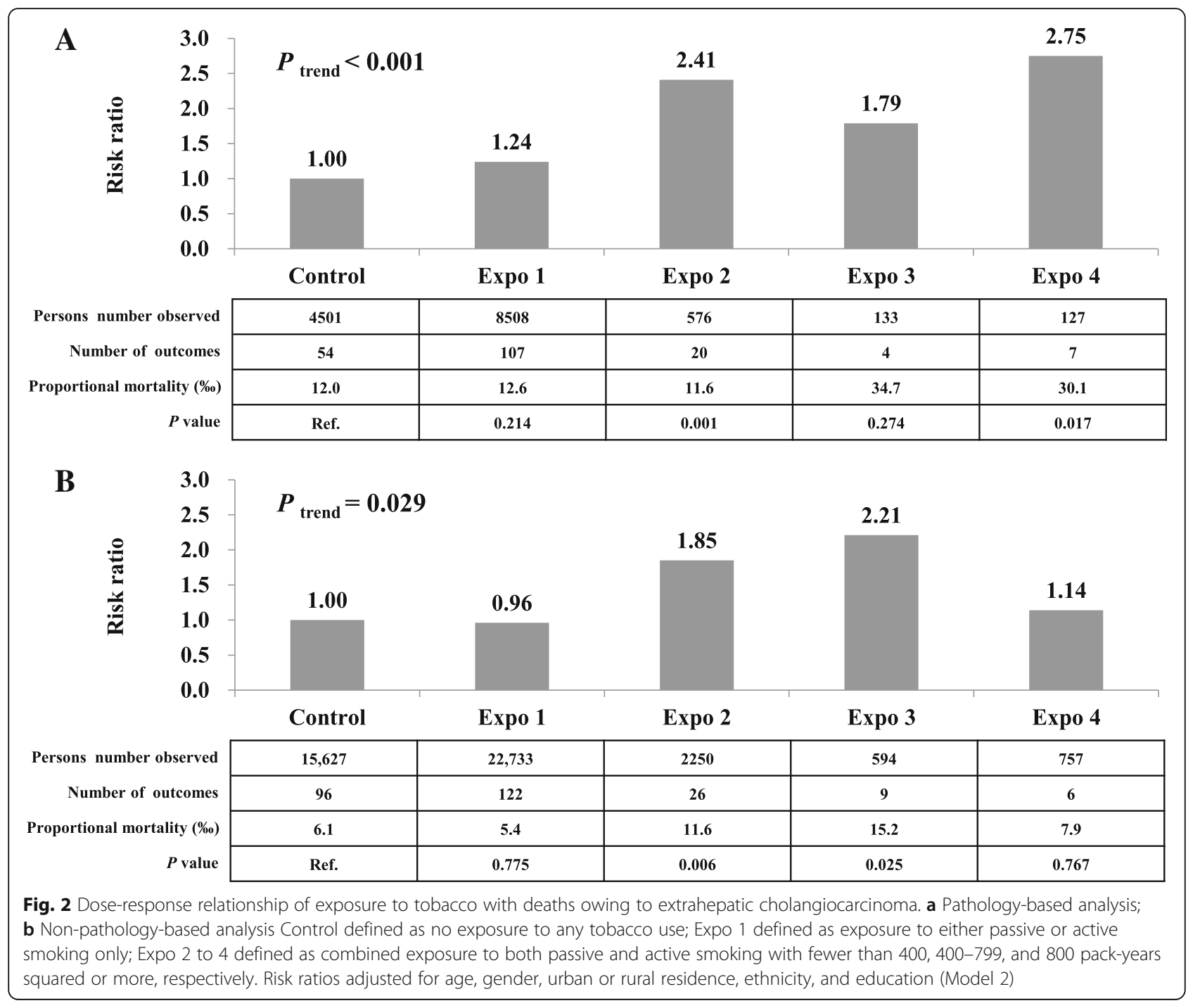

Table 4 Sensitivity analysis for 269 participants with non-pathology-based diagnoses or digestive diseases other than cholangiocarcinoma

\begin{tabular}{|c|c|c|c|c|c|}
\hline \multirow{2}{*}{$\begin{array}{l}\% \text { changed } \\
\text { to non-cases }\end{array}$} & \multirow{2}{*}{$\begin{array}{l}\text { Number of } \\
\text { cases changed }\end{array}$} & \multicolumn{4}{|c|}{ RR $(95 \% \mathrm{Cl})^{*}$ for exposure to tobacco } \\
\hline & & Passive & Active & Passive \& Active & All \\
\hline 100 & 269 & $1.34(0.81-2.21)$ & $1.38(0.90-2.12)$ & $2.52(1.58-4.00)$ & $1.39(1.00-1.93)$ \\
\hline 90 & 243 & $1.26(0.79-2.00)$ & $1.39(0.93-2.04)$ & $2.53(1.65-2.88)$ & $1.40(1.03-1.90)$ \\
\hline 80 & 215 & $1.39(0.90-2.14)$ & $1.29(0.88-1.87)$ & $2.52(1.70-3.76)$ & $1.41(1.06-1.88)$ \\
\hline 70 & 188 & $1.43(0.97-2.10)$ & $0.99(0.70-1.40)$ & $1.91(1.30-2.82)$ & $1.18(0.91-1.54)$ \\
\hline 60 & 160 & $1.51(1.05-2.18)$ & $0.96(0.69-1.33)$ & $1.97(1.37-2.84)$ & $1.21(0.94-1.55)$ \\
\hline 50 & 135 & $1.42(1.00-2.03)$ & $1.15(0.83-1.58)$ & $2.27(1.61-3.31)$ & $1.33(1.04-1.70)$ \\
\hline 40 & 108 & $1.14(0.82-1.59)$ & $1.01(0.75-1.37)$ & $1.87(1.34-2.60)$ & $1.13(0.90-1.41)$ \\
\hline 30 & 81 & $1.16(0.84-1.60)$ & $1.08(0.81-1.44)$ & $1.95(1.42-2.69)$ & $1.18(0.95-1.47)$ \\
\hline 20 & 54 & $1.19(0.87-1.62)$ & $1.01(0.76-1.34)$ & $1.95(1.44-2.65)$ & $1.17(0.94-1.44)$ \\
\hline 10 & 27 & $1.20(0.89-1.63)$ & $1.07(0.82-1.40)$ & $1.92(1.42-2.58)$ & $1.21(0.99-1.49)$ \\
\hline
\end{tabular}

*Adjusted for age, gender, urban or rural residence, ethnicity, education, and pathology-based or non-pathology-based diagnosis (Model 2) 
change in exposure locations from predominantly in the home to a dramatic increase of smoking in public spaces, including in the workplace [33]. Surveys have also suggested that a growing population of smokers is exposed to passive smoking, and our data included many such individuals. The International Tobacco Control Policy Evaluation China Survey indicated compared with nonsmokers, smokers are more likely to be exposed to secondhand smoke owing to lower levels of about the harm of secondhand smoke [34]. Our study further indicated greater harms owing to combined tobacco exposure in this population than that for nonsmokers exposed to passive smoking. More importantly, high rates of exposure to tobacco are associated with a broad spectrum of diseases. As implied in our study, high rates of exposure to secondhand smoke likely increase the incidence of some rare and refractory cancers, such as ECC. The dramatic increase in such cases poses a challenge to current medical services and public health services, considering that there are much fewer studies on such cancers than those for more common malignancies. We suggest that the age peak for ECC occurrence in China is much earlier than that in the developed countries [9]; our study findings indicate that the association of exposure to tobacco with ECC is particularly prominent among people aged 50 years or older, representing nearly $90 \%$ of ECC cases. Such findings could contribute to risk stratification and case detection among patients attending ECC clinics for the diagnosis and treatment of ECC.

A key strength of this research is that despite being a retrospective study, this was a large population-based study across China in which temporality could be established owing to a high fatality rate of this disease and a time interval of more than 5 years between exposure and outcome. High fatality in this cancer also reduced competing risks from other deaths and risk of exposure change from occurrence of this disease. In addition, we firstly demonstrated dose-relationships between all types of exposure to tobacco and ECC risk as well as interaction between different exposures. Lastly, we used sensitivity analyses to address concerns regarding a retrospective study, such as prevalence of ECC at the beginning time of exposure and misclassification owing to diagnosis; robust results were retained in all analyses.

This study has some limitations. First, although the participants included into this analysis were all from source population, owing to the proportional mortality design and exclusion of some deaths related to smoking, the association between exposure to smoking and ECC could not be established; thus, further evidence is required. Second, the source of passive smoking might be from public areas; however, a low rate of tobacco exposure in public spaces, including workplaces (5.74\%), from the 1984 National Smoking Survey of China suggests that study participants had little likelihood of being exposed to tobacco in public spaces. Third, based on the previously low rate of quitting smoking (4.78\%) in China, participant behaviors would not be substantially changed between exposure and death owing to ECC. Fourth, we could not completely exclude likely confounding from chronic disorders such as parasitic infections, hepatolithiasis, and liver diseases. However, there was likely to be little bias owing to the exclusion criteria used (although these might have led to selection bias), sensitivity analysis conducted, and little established association between these disorders and ECC. Finally, exposure to passive smoking seemed associated with higher risk of ECC than exposure to active smoking in some subgroups; this was related to a smaller sample size after stratification and weak effect of exposure on this disease. Nevertheless, these limitations would not change our main findings. Additionally, our dataset is old, but this did not affect our exploration of this association because this is the only national dataset on this topic that includes spousal information. Moreover, the large sample size could yield sufficient outcomes defined as relatively rare cancers and etiological associations cannot be unchanged over time.

\section{Conclusions}

This study provides the first evidence to support an association of exposure to tobacco with ECC. Given the notably increased ECC risk from passive plus active smoking and a dramatic increase of exposure to secondhand smoke, attention should be given to any change in the tobacco-associated disease spectrum. Tobacco prevention and cessation programs, and provision of smoke-free environments in particular, could contribute to staving off a sharp increase of ECC in China.

\section{Additional file}

Additional file 1: Table S1. Characteristics of excluded participants. Table S2. Association between exposure and deaths owing to extrahepatic cholangiocarcinoma, considering the assumed age of marriage. (DOCX $16 \mathrm{~kb}$ )

\section{Abbreviations}

CC: Cholangiocarcinoma; Cl: Confidence interval; ECC: Extrahepatic cholangiocarcinoma; ICC: Intrahepatic cholangiocarcinoma; ICD9: International Classification of Diseases, 9th Revision; OR: Odds ratio; RR: Risk ratio

\section{Acknowledgements}

We thank Professor Richard Peto, the local governments, and the many doctors, nurses, and other field workers who provided their support to this project. We thank Analisa Avila, ELS, of Liwen Bianji, Edanz Group China (www.liwenbianji.cn/ac), for editing the English text of a draft of this manuscript. 


\section{Funding}

The Medical Research Council and Imperial Cancer Research Fund in Britain US National Institutes of Health, Chinese Ministry of Health, and Chinese Academy of Medical Sciences funded the design of the original survey and data collection. This work, including the analyses, decision to publish, and preparation of the manuscript, was supported by a UICC International Cancer Technology Transfer Fellowship under Contract No. ICR/13/073/2013 UICC.

\section{Availability of data and materials}

The datasets used and analyzed during the current study are available from the corresponding author on reasonable request.

\section{Authors' contributions}

LH conceived the hypothesis and wrote the manuscript; $J$ J and BL ensured the data quality and reviewed the manuscript; $L H, W H, F X, B Z, H P, Y W 2, Z W$, and $\mathrm{YH}$ analyzed the data; $\mathrm{YW1}, \mathrm{XZ}, \mathrm{YC}, \mathrm{BL}$, and $\mathrm{JL}$ collected data. All authors read and approved the final manuscript.

\section{Ethics approval and consent to participate}

Retrospective information collected was limited to smoking exposure only, and oral informed consent for this study, without any intervention, was obtained. The data accessed from the survey was de-identified. It was recognized that the right and the welfare of the subjects in this study were adequately protected; the potential benefits from this study and the potential risks to subjects were within a reasonable range. We retrospectively obtained the ethical approval from the INSTITUTIONAL REVIEW BOARD of Institute of Basic Medical Sciences, Chinese Academy of Medical Sciences that reviewed the proposed use of human subjects.

\section{Consent for publication}

Not Applicable.

\section{Competing interests}

The authors declare that they have no competing interests.

\section{Publisher's Note}

Springer Nature remains neutral with regard to jurisdictional claims in published maps and institutional affiliations.

\section{Author details \\ 'Department of Epidemiology and Biostatistics, Institute of Basic Medical Sciences Chinese Academy of Medical Sciences / School of Basic Medicine Peking Union Medical College, A505 Room Mingri Building, 5 Dongdansantiao Street, Dongcheng District, Beijing 100005, China. ${ }^{2}$ Cancer Institute \& Hospital, Chinese Academy of Medical Sciences / Peking Union Medical College, Beijing, China. ${ }^{3}$ National Center for Chronic and Noncommunicable Disease Control and Prevention, Chinese Center for Disease Control and Prevention, Beijing, China.}

Received: 31 January 2019 Accepted: 15 March 2019 Published online: 11 April 2019

\section{References}

1. Banales JM, Cardinale V, Carpino G, Marzioni M, Andersen JB, Invernizzi P, Lind GE, Folseraas T, Forbes SJ, Fouassier L, Geier A, Calvisi DF, Mertens JC, Trauner M, Benedetti A, Maroni L, Vaquero J, Macias RI, Raggi C, Perugorria MJ, Gaudio E, Boberg KM, Marin JJ, Alvaro D. Expert consensus document: Cholangiocarcinoma: current knowledge and future perspectives consensus statement from the European Network for the Study of Cholangiocarcinoma (ENS-CCA). Nat Rev Gastroenterol Hepatol. 2016;13(5):261-80.

2. Zhou M, Wang H, Zhu J, Chen W, Wang L, Liu S, Li Y, Wang L, Liu Y, Yin P, Liu J, Yu S, Tan F, Barber RM, Coates MM, Dicker D, Fraser M, GonzálezMedina D, Hamavid H, Hao Y, Hu G, Jiang G, Kan H, Lopez AD, Phillips MR, She J, Vos T, Wan X, Xu G, Yan LL, Yu C, Zhao Y, Zheng Y, Zou X, Naghavi M, Wang Y, Murray CJ, Yang G, Liang X. Cause-specific mortality for 240 causes in China during 1990-2013: a systematic subnational analysis for the Global Burden of Disease Study 2013. Lancet. 2016;387(10015):251-72.

3. Gatto M, Bragazzi MC, Semeraro R, Napoli C, Gentile R, Torrice A, Gaudio E, Alvaro D. Cholangiocarcinoma: update and future perspectives. Dig Liver Dis. 2010;42(4):253-60.

4. Razumilava N, Gores GJ. Cholangiocarcinoma. Lancet. 2014;383(9935):2168-79.
5. Edge SB, Compton CC. The American joint committee on Cancer: the 7th edition of the AJCC cancer staging manual and the future of TNM. Ann Surg Oncol. 2010;17(6):1471-4.

6. Khan SA, Emadossadaty S, Ladep NG, Thomas HC, Elliott P, Taylor-Robinson SD, Toledano MB. Rising trends in cholangiocarcinoma: is the ICD classification system misleading us? J Hepatol. 2012;56(4):848-54.

7. Welzel TM, McGlynn KA, Hsing AW, O'Brien TR, Pfeiffer RM. Impact of classification of hilar cholangiocarcinomas (Klatskin tumors) on the incidence of intra- and extrahepatic cholangiocarcinoma in the United States. J Natl Cancer Inst. 2006;98(12):873-5.

8. Hsing AW, Gao YT, Devesa SS, Jin F, Fraumeni JF Jr. Rising incidence of biliary tract cancers in Shanghai. China Int J Cancer. 1998;75(3):368-70.

9. Bao PP, Zheng Y, Wu CX, Huang ZZ, Gao YT, Jin F, Xiang YB, Zhong WJ, Lu W, Wu F. Cancer incidence in urban Shanghai, 1973-2010: an updated trend and age-period-cohort effects. BMC Cancer. 2016;16(1):284.

10. Jensen K, Afroze S, Ueno Y, Rahal K, Frenzel A, Sterling M, Guerrier M, Nizamutdinov D, Dostal DE, Meng F, Glaser SS. Chronic nicotine exposure stimulates biliary growth and fibrosis in normal rats. Dig Liver Dis. 2013; 45(9):754-61.

11. Yu MW, Yang SY, Chiu YH, Chiang YC, Liaw YF, Chen CJ. A p53 genetic polymorphism as a modulator of hepatocellular carcinoma risk in relation to chronic liver disease, familial tendency, and cigarette smoking in hepatitis B carriers. Hepatology. 1999;29(3):697-702.

12. McCue JM, Link KL, Eaton SS, Freed BM. Exposure to cigarette tar inhibits ribonucleotide reductase and blocks lymphocyte proliferation. J Immunol. 2000;165(12):6771-5.

13. Khan SA, Davidson BR, Goldin RD, Heaton N, Karani J, Pereira SP, Rosenberg WM, Tait P, Taylor-Robinson SD, Thillainayagam AV, Thomas HC, Wasan H. Guidelines for the diagnosis and treatment of cholangiocarcinoma: an update. Gut. 2012;61(12):1657-69.

14. Li Q, Hsia J, Yang G. Prevalence of smoking in China in 2010. N Engl J Med. 2011;364(25):2469-70.

15. Yang G. Marketing 'less harmful, low-tar' cigarettes is a key strategy of the industry to counter tobacco control in China. Tob Control. 2014; 23(2):167-72.

16. Ye XH, Huai JP, Ding J, Chen YP, Sun XC. Smoking, alcohol consumption, and the risk of extrahepatic cholangiocarcinoma: a meta-analysis. World J Gastroenterol. 2013;19(46):8780-8.

17. Petrick JL, Yang B, Altekruse SF, Van Dyke AL, Koshiol J, Graubard BI, McGlynn KA. Risk factors for intrahepatic and extrahepatic cholangiocarcinoma in the United States: a population-based study in SEERMedicare. PLoS One. 2017;12(10):e0186643.

18. Welzel TM, Graubard BI, El-Serag HB, Shaib YH, Hsing AW, Davila JA, McGlynn KA. Risk factors for intra-hepatic and extra-hepaxtrahepatic cholangiocarcinoma in the United States: a population-based case-control study. Clin Gastroenterol Hepatol. 2007;5(10):1221-8.

19. Moerman CJ, Bueno de Mesquita HB, Runia S. Smoking, alcohol consumption and the risk of cancer of the biliary tract; a population-based case-control study in the Netherlands. Eur J Cancer Prev. 1994:3(5):427-36.

20. Khan ZR, Neugut Al, Ahsan H, Chabot JA. Risk factors for biliary tract cancers. Am J Gastroenterol. 1999:94(1):149-52.

21. Chow WH, McLaughlin JK, Menck HR, Mack TM. Risk factors for intrahepatic and extrahepatic cholangiocarcinoma: a hospital-based case-control study. Am J Gastroenterol. 2007;102(5):1016-21.

22. Chow WH, McLaughlin JK, Menck HR, Mack TM. Risk factors for extrahepatic bile duct cancers: Los Angeles County, California (USA). Cancer Causes Control. 1994;5(3):267-72.

23. Brandi G, Di Girolamo S, Farioli A, de Rosa F, Curti S, Pinna AD, Ercolani G, Violante FS, Biasco G, Mattioli S. Asbestos: a hidden player behind the cholangiocarcinoma increase? Findings from a case-control analysis. Cancer Causes Control. 2013;24(5):911-8.

24. Jiang J, Liu B, Sitas F, Li J, Zeng X, Han W, Zou X, Wu Y, Zhao P. Smokingattributable deaths and potential years of life lost from a large, representative study in China. Tob Control. 2010;19(1):7-12.

25. Liu BQ, Peto R, Chen ZM, Boreham J, Wu YP, Li JY, Campbell TC, Chen JS. Emerging tobacco hazards in China: 1. Retrospective proportional mortality study of one million deaths. BMJ. 1998;317(7170):1411-22.

26. Jiang JM, Zeng XJ, Chen JS, Ping-zhao LY, Zhang KL, Wu YP, Liu BQ. Smoking and mortality from esophageal cancer in China: a large casecontrol study of 19,734 male esophageal cancer deaths and 104,846 living spouse controls. Int J Cancer. 2006;119(6):1427-32. 
27. Hou L, Han W, Jiang J, Liu B, Wu Y, Zou X, Xue F, Chen Y, Zhang B, Pang H, Wang $Y$, Wang $Z$, Hu Y, Li J. Passive smoking and stroke in men and women: a national population-based case-control study in China. Sci Rep. 2017;7:45542.

28. Jiang J, Pang H, Liu B, Nasca PC, Zhang B, Wu Y, Han W, Gates M, Lu T, Zou X, Xue F, Hou L, Wang Z, Wang Y, Chen Y, Li J. Effects of active, passive, and combined smoking on cervical cancer mortality: a nationwide proportional mortality study in Chinese urban women. Cancer Causes Control. 2015;26(7):983-91.

29. Hou L, Jiang J, Liu B, Nasca PC, Wu Y, Zou X, Han W, Chen Y, Zhang B, Xue F, Pang H, Li J. Association between smoking and deaths due to colorectal malignant carcinoma: a national population-based case-control study in China. Br J Cancer. 2014;110(5):1351-8.

30. Wang Y. Peasants' behavior in their first marriage under the legal marriage age and late-marriage policy: an analysis based on the data of the fifth census. Chinese Journal of Population Science. 2005:4:79-89 Chinese.

31. Everhart JE, Ruhl CE. Burden of digestive diseases in the United States part III: liver, biliary tract, and pancreas. Gastroenterology. 2009:136(4):1134-44.

32. Yang $G$, Wang $Y$, Wu Y, Yang J, Wan $X$. The road to effective tobacco control in China. Lancet. 2015;385(9972):1019-28.

33. GATS China Workgroup. Global Adult Tobacco Survey (GATS) China 2010 Country report. In: Chinese Center for Disease Control and Prevention. Beijing: China Three Gorges Publishing House. p. 2011.

34. Feng $G$, Jiang $Y$, Zhao $L$, et al. Degree of exposure to secondhand smoking and related knowledge, attitude among adults in urban China. Zhonghua Liu Xing Bing Xue Za Zhi. 2014;35(9):998-1001 Chinese.

Ready to submit your research? Choose BMC and benefit from:

- fast, convenient online submission

- thorough peer review by experienced researchers in your field

- rapid publication on acceptance

- support for research data, including large and complex data types

- gold Open Access which fosters wider collaboration and increased citations

- maximum visibility for your research: over $100 \mathrm{M}$ website views per year

At BMC, research is always in progress.

Learn more biomedcentral.com/submissions 